\title{
Nutritional Status of Rural Bengali Adolescent Boys of Tripura: Author's Reply
}

\author{
Sandeep Roy Sarkar ${ }^{1}$
}

Received: 18 December 2015 / Accepted: 11 January 2016/Published online: 11 February 2016

(C) Dr. K C Chaudhuri Foundation 2016

To the Editor: I welcome the queries on my research article

[1]. I have the following replies:

1. Socioeconomic status was determined by updated Kuppuswamy's socioeconomic scale [2].

2. WHO charts for 5-18 y-old children are based on statistical reconstruction of 1977 National Centre for Health Statistics data [3]. WHO has stated that it would not be possible to have prescriptive growth standards for children between 5 and $18 \mathrm{y}$ of age because of environmental variables. Hence, it is necessary to have country-specific growth charts. The revised IAP growth charts for 5-18 y old Indian children are based on data collated from different regions of India [4]. We made the assessment of nutritional status using both international and national growth references.

3. The overall prevalence of stunting, thinness, overweight and obesity were observed $21.15 \%, 40.32 \%, 4.30 \%$ and $0.36 \%$ respectively using WHO reference data [5] while using the IAP growth charts [4] as reference, the overall

Sandeep Roy Sarkar

sndprysrkr@rediffmail.com

1 Department of Human Physiology, Tripura University, Suryamaninagar, Agartala, Tripura 799022, India prevalence of stunting, thinness, overweight and obesity were observed $9.09 \%, 12 \%, 7.09 \%$ and $0.36 \%$ respectively. Thus, using the country-specific growth charts (IAP growth charts), a lower rate in the overall prevalence of undernutrition (stunting, thinness) and a higher rate in the overall prevalence of overnutrition (overweight) was found.

\section{Compliance with Ethical Standards}

Conflict of Interest None.

Source of Funding None.

\section{References}

1. Sarkar SR, Sil SK. Nutritional status of rural Bengali adolescent boys of Tripura. Indian J Pediatr. 2015. doi:10.1007/s12098-015-1856-6.

2. Kumar N, Gupta N, Kishore J. Kuppuswamy's socioeconomic scale: updating income ranges for the year 2012. Indian J Public Health. 2012;56:103-4.

3. de Onis M, Onyango AW, Borghi E, Siyam A, Nishida C, Siekmann J. Development of a WHO growth reference for school-aged children and adolescents. Bull World Health Organ. 2007;85:660-7.

4. Khadilkar V, Yadav S, Agrawal KK, et al. Revised IAP growth charts for height, weight and body mass index for 5 to 18 year old Indian children. Indian Pediatr. 2015;52:47-55.

5. World Health Organization. Growth Reference Data for 5-19 years. 2007. Available from URL: http://www.who.int/growthref/ who2007/en/index.html. Assessed on September 10, 2014. 